The second peak of the absorption curves observed in the group 3 patients (fig. 3 ) is probably explained by "biliary recycling." This observation was unexpected and therefore not studied under ideally controlled circumstances with standardized meals and at standardized time after digoxin administration. But the evidence is striking all the same. It may indicate that the drug is excreted in the bile and reabsorbed when food is given. Another explanation is that the bile enhances the absorption of the drug present in the bowel. White et al. (1971) found that the absorption of digoxin was reduced when the drug was given after food. It is therefore unlikely that the food by itself inceased the absorption and gave the second peak observed.

When the same maintenance dose of $\mathrm{L} 1$ and $\mathrm{L} 2$ was given, there was a little difference in the plasma levels of digoxin 15 hours after the dose (table I). This indicates that the excretion rate or metabolization of digoxin was greater for $\mathbf{L} 2$ than for L 1 . Since the urinary excretion was increased only about $40 \%$ when L 1 was replaced by L 2 (table II), an increase in metabolization or intestinal excretion is suggested. If the "second peak" observed (fig. 3) represents biliary recycling this indicates that the amount of digoxin excreted in the bile when $\mathrm{L} 2$ was given is important. Because of the rapid absorption of $\mathrm{L} 2$ the level of digoxin in the portal vein and in the liver is higher for $\mathrm{L} 2$ than for $\mathrm{L} 1$ during the first hours after the administration of the drug. The biliary excretion of digoxin must, therefore, be expected to be greater for $\mathrm{L} 2$ than for $\mathrm{L} 1$ as digoxin is eliminated on first order kinetics. A greater biliary excretion of digoxin from the systemic circulation should also be expected for $\mathrm{L} 2$ because of higher plasma levels.

The absorption curves after the dose of $1.0 \mathrm{mg}$ of $\mathrm{L} 1$ and $0.5 \mathrm{mg}$ of $\mathrm{L} 2$ are almost parallel after constant plasma levels were obtained (fig. 2). This suggests that digoxin in plasma from $\mathrm{L} 1$ and $\mathrm{L} 2$ is handled in the same manner. The difference in metabolization and excretion therefore seems to be a matter of plasma concentration.

The constant plasma levels obtained after ingestion of 1.0 mg L 1 ought to be higher than after a dose of $0.5 \mathrm{mg} \mathrm{L} 2$. The equal plasma levels 15 hours after administration of 0.5 $\mathrm{mg}$ of $\mathrm{L} 2$ and $1.0 \mathrm{mg}$ of $\mathrm{L} 1$ (group 2, fig. 2) seems to con- flict with the equal levels 15 hours after the same maintenance dose of $\mathrm{L} 1$ and $\mathrm{L} 2$ given to the patients of group 3 (table I). This might be explained by characteristics of the digoxin assay, since the concentrations after equilibrium in group 2 are at the lowermost end of the range of sensitivity for the radioimmunoassay. A difference in metabolic clearance rate between digoxin given in a single dose and on a constant maintenance dose is, however, possible.

The shape of the absorption curves for $L 1$ and $L 2$ is influenced by a difference in absorption rates. Before the equilibrium the new drug shows a faster rate of fall than the old (fig 2). This might be partly explained by a more rapid excretion of $\mathrm{L} 2$ because of higher concentration. In addition, the slow absorption of L 1 may continue for several hours and thereby influence the curve for its disappearance rate.

The relation of nausea to peak blood levels observed in five of the subiects in group 1, and the more rapid fall off of the new digoxin should be emphasized. This means that L 2 is more toxic than L 1 for only a few hours after the dose is given. It can therefore be recommended that the daily dose be subdivided in order to avoid too high peak levels shortly after the administration.

Our observations do not indicate that the new digoxin should be given in half the dosage of the old, as has previously been recommended. A dose of $0.125 \mathrm{mg}$ twice daily of $\mathrm{L}_{2}$ given to elderly patients is usually sufficient to reach a plasma level within the recommended therabeutic range between 1 and $2 \mathrm{ng} / \mathrm{ml}$. Young people need a higher dosage. If the kidney function is reduced at least $50 \%$ (glomerular filtration rate, renal plasma flow) (Falch, 1973b) the dosage has to be reduced according to the reduction in the kidney function.

\section{References}

Falch, D. (1973a). Fournal of Oslo City Hospital. In press.

Falch, D. (1973b). Acta Medica Scandinavica. In press.

Lindebaum, J., Mellow, M. H., Blackstone, M. O., and Butler, V. P. (1971). New England Fournal of Medicine, 285, 1344 .

Manninen, V., Malin, J., and Härtel, G. (1971). Lancet, 2, 934

Shaw, T. R. D., Howard, M. R., and Hamer, J. (1972). Lancet, 2, 303. White, R. J., Chamberlain, D. A., Howard, M., and Smith, T. W. (1971) British Medical Fournal, 1, 380.

\title{
Bubble Stability Test Compared with Lecithin Assay in Prediction of Respiratory Distress Syndrome
}

\author{
S. G. BHAGWANANI, D. FAHMY, A. C. TURNBULL
}

British Medical fournal, 1973, 1, 697-700

\section{Summary}

A simple test for surfactant, utilizing bubble stability in ethanol, was performed in 106 samples of amniotic fluid obtained from 94 patients. Of these patients 80

\footnotetext{
Department of Obstetrics and Gynaecology, Welsh National School of Medicine, The Maternity Hospital, Cardiff CF2 1XF

S. G. BHAGWANANI, M.D., Research Fellow

D. FAHMY, PH.D., Principal Biochemist

A. C. TURNBULL, M.D., F.R.C.O.G., Professor of Obstetrics and Gynaecology
}

delivered within $\mathbf{4 8}$ hours of the collection of the sample. The results were compared with the lecithin concentration in the same amniotic fluid samples and with the quality of respiration in the neonate. The test was "positive," indicating fetal pulmonary maturity, in 37 cases and none of these infants developed respiratory distress syndrome (R.D.S.). In only one of these cases, however, was gestation less than 37 weeks. The test was "intermediate" or "negative" in 43 cases but in 35 of these infants respiration at birth was perfectly normal.

Performed by the method described by its originators, this simple test gives too many false negative results to be of value in routine clinical practice, although a positive result is helpful. The concept of the test is ingenious, however, and further developments may be expected. 


\section{Introduction}

Clements et al. (1972) described a simple, quick, and inexpensive test for the antenatal prediction of the potential risk of respiratory distress syndrome (R.D.S.) in the newborn. The test is based on the ability of pulmonary surfactant in amniotic fluid to form stable films that can support the structure of a foam for relatively long periods. Other substances in amniotic fluid such as proteins, bile salts, and salts of free fatty acids which can also form stable foams are excluded from the surface films by the non-foaming competitive surfactant, ethanol.

The lecithin concentration of amniotic fluid seems to be a sensitive index of fetal lung maturity (Bhagwanani et al., 1972a; Nelson, 1972). A lecithin concentration of $3.5 \mathrm{mg} / 100 \mathrm{ml}$ seems to be critical, since values greater than this are associated with normal respiration while lower levels are likely to be associated with R.D.S. in the newborn (Bhagwanani et al., 1972a). Since the test described by Clements and his colleagues is so much quicker and easier to perform than the most rapid method developed for the biochemical measurement of lecithin in amniotic fluid (Bhagwanani et al., 1972b) and potentially useful for routine clinical practice, we have compared its value in predicting R.D.S. with that of lecithin assay.

\section{Materials and Methods}

Altogether, 106 samples of amniotic fluid were obtained from 94 patients of whom 80 delivered within 48 hours of the collection. Sixty-three samples were obtained at the time of artificial rupture of the membranes (usually with a Drew Smythe catheter), 35 by amniocentesis, and the remaining eight at elective caesarean section. Great care was taken to avoid contamination with antiseptics or vaginal secretion. If such contamination did occur, or if the sample was blood or meconium stained, it was discarded. Over $75 \%$ of amniotic fluid samples were assayed within two hours of collection, the remainder being stored at $-20^{\circ} \mathrm{C}$ and assayed not more than 24 hours after collection.

The test for bubble stability in amniotic fluid was performed exactly as described by Clements et al. (1972). No modifications were introduced and all the precautions advised by these workers were taken. Varying amounts of amniotic fluid (1.00, $0.75,0.50,0.25$, and $0.20 \mathrm{ml}$ ) were placed in 8 by $100 \mathrm{~mm}$ glass tubes and made up to a fixed volume of $1 \mathrm{ml}$ with normal saline. After addition of $1 \mathrm{ml}$ of $95 \%$ ethanol the tubes were vigorously shaken for 15 seconds and allowed to stand for 15 minutes. The presence of a complete ring of bubbles in the first three tubes was taken as indicating a "positive" result. The absence of such a ring in the first tube indicated a "negative" result, while its presence in the first, or in the first and second tubes, indicated an "intermediate" result.

Clements and his associates considered a positive result to indicate fetal pulmonary maturity and therefore associated with a negligible risk of neonatal R.D.S. A negative result, on the other hand, appeared to carry a $100 \%$ risk of R.D.S. in the infants delivered within $\mathbf{4 8}$ hours of the test.

The lecithin concentration in amniotic fluid was determined by the procedure previously reported (Bhagwanani et al., 1972b). This involved chloroform methanol extraction of lipids from amniotic fluid followed by separation of the phospholipids in the extract by chromatography on thin layers of silica gel. The lecithin band is eluted and lecithin determined indirectly by measuring its phosphorus content.

R.D.S. was diagnosed in the presence of clinical and radiological evidence of the disease. The severity of the disease was assessed by a paediatrician who did not know the result of the bubble stability test or lecithin levels.

\section{Results}

The results of the bubble stability test in 106 samples of amniotic fluid obtained at various stages of gestation are given in table $I$.
TABLE I-Bubble Stability in Ethanol in 106 Samples of Amniotic Fluid Obtained at Varying Stages of Gestation

\begin{tabular}{|c|c|c|c|c|c|c|}
\hline & \multirow{2}{*}{\multicolumn{3}{|c|}{$\begin{array}{l}\text { Gestation in } \\
\text { Weeks }\end{array}$}} & \multicolumn{3}{|c|}{ Bubble Stability in Ethanol } \\
\hline & & & & \multirow[b]{2}{*}{$\begin{array}{c}\text { Negative } \\
18 \\
14 \\
4 \\
5 \\
4 \\
1 \\
=\end{array}$} & \multirow{2}{*}{$\begin{array}{c}\text { Intermediate } \\
1 \\
1 \\
5 \\
5 \\
3 \\
4 \\
3 \\
1\end{array}$} & \multirow[b]{2}{*}{$\begin{array}{c}\text { Positive } \\
- \\
71 \\
5 \\
5 \\
12 \\
9 \\
5\end{array}$} \\
\hline $\begin{array}{r}\leqslant 35 \\
36 \\
37 \\
38 \\
39 \\
40 \\
41 \\
42\end{array}$ & $\begin{array}{l}. \\
\because \\
\because \\
\because \\
\because \\
\therefore \\
.\end{array}$ & $\begin{array}{l}\ldots \\
\cdots \\
\cdots \\
\cdots \\
\cdots \\
\cdots\end{array}$ & $\begin{array}{l}\because \\
\because \\
\because \\
\because \\
\therefore\end{array}$ & & & \\
\hline
\end{tabular}

There is a definite relation between the stage of gestation and the results of the test. In general, the earlier the gestation the greater the proportion of negative tests. For example, of 44 amniotic fluids examined before the 38th week, 36 gave a negative test, seven were intermediate, and only one was positive. In contrast, after the end of the 39th week a negative result was found in only one case, where the baby subsequently developed R.D.S., while most (26 out of 35 ) amniotic fluids tested were positive.

Comparison is made in table II of the results obtained with the bubble stability test and the lecithin concentration in the same sample with the quality of neonatal respiration in 80 cases delivered within 48 hours of the collection of the sample. This group was selected because lecithin and presumably pulmonary surfactant concentration can rise appreciably in a relatively short time interval (Bhagwanani et al., 1972a; Gluck et al., 1971). Of these 80 infants, 72 breathed normally and eight either developed R.D.S. or had hypoplastic and atelectatic lungs at necropsy.

TABLE II-Relation between Bubble Stability in Ethanol, Respiratory Status of the Newborn, and Lecithin Concentration in 80 Samples of Amniotic Fluid Collected within 48 Hours of Delivery

\begin{tabular}{|c|c|c|c|c|}
\hline $\begin{array}{c}\text { Bubble } \\
\text { Stability } \\
\text { in Ethanol }\end{array}$ & $\begin{array}{c}\text { Lecithin } \\
\text { Concentration } \\
\text { (mg/100 ml) } \\
\text { (Mean and Range) }\end{array}$ & $\begin{array}{l}\text { No. of } \\
\text { Cases }\end{array}$ & $\begin{array}{c}\text { No. of } \\
\text { Cases with } \\
\text { Normal Respiration }\end{array}$ & $\begin{array}{c}\text { No. of } \\
\text { Cases with } \\
\text { R.D.S.* }\end{array}$ \\
\hline Negative & $\begin{array}{r}4.80 \\
(0.92-10 \cdot 1)\end{array}$ & 25 & 19 & 6 \\
\hline Intermediate & $8 \cdot 60$ & 18 & 16 & 2 \\
\hline Positive & $\begin{array}{c}14 \cdot 75 \\
(7 \cdot 10-24 \cdot 0)\end{array}$ & 37 & 37 & - \\
\hline
\end{tabular}

* Two cases with intermediate results died soon after birth and had hypoplastic atelectatic lungs at necropsy.

Positive results of the bubble stability test were obtained in 37 cases and every infant in this group had normal respiration. Intermediate results were obtained in 18 cases and two of the infants had hypoplastic atelectatic lungs. One was thought to be of 36 weeks' gestation although she weighed only $900 \mathrm{~g}$ and died within six hours of birth. The other infant was anencephalic and weighed $1,100 \mathrm{~g}$. Negative results were obtained in 25 cases, and in six the infant developed R.D.S. Thus all of the eight infants who developed R.D.S. or had hypoplastic atelectatic lungs had either a negative or an intermediate result on predelivery testing of bubble stability in amniotic fluid.

The results of the bubble test in 80 cases where the amniotic fluid was collected within $\mathbf{4 8}$ hours of delivery are shown in the chart. As would be expected, the proportion of cases with a positive result rises with increasing gestational age. Although all cases where the infant developed R.D.S. had negative or intermediate results, it is clearly shown that a large number of infants with these theoretically unfavourable results breathed normally.

A comparison is made in table III of the accuracy of measuring bubble stability in amniotic fluid with lecithin concentration in predicting potential R.D.S. It is immediately apparent that the simple bubble stability test gives far too high a proportion of 


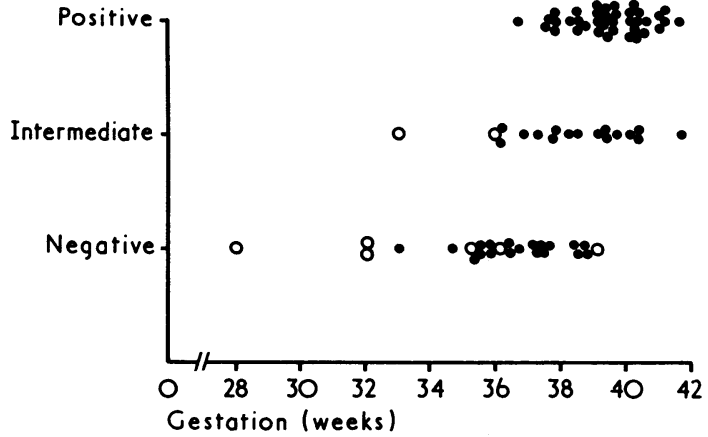

Results of the bubble stability in 80 cases where the amniotic fluid was collected within 48 hours of delivery. amniotic fluid was collected within drome, or hypoplastic, atelectatic lungs.

TABLE III-Comparison between Amniotic Fluid Lecithin Concentration and Bubble Stability in Ethanol in the Antenatal Prediction of Potential R.D.S. in 80 Cases

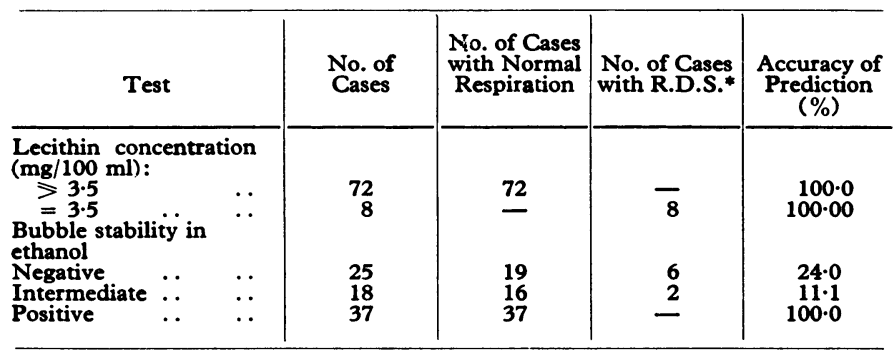

- Two cases with intermediate results died soon after birth and had hypoplastic atelectatic lungs at necropsy.

negative and intermediate results, suggesting a potential risk of R.D.S. which did not exist. Although all infants delivered within 48 hours of a positive bubble test had normal respiration, it must be remembered that no positive test was ever obtained before the end of the 36th week of gestation. By comparison, a lecithin level above $3.5 \mathrm{mg} / 100 \mathrm{ml}$ found within 48 hours of delivery at any stage of gestation will be associated with normal breathing in the neonate.

\section{Discussion}

Normal respiration in the neonate depends not only on lung maturation but also on the ability of the lung tissue to synthesize a specific lipoprotein, which effectively lowers surface tension and thereby maintains alveolar stability. This lipoprotein, extracted with saline from fetal lungs at varying stages of gestation, is thought to have the protein moiety conjugated to a variety of phospholipids, the most important of which is supposed to be the dipalmitoyl derivative of lecithin.

During development there is preferential synthesis of the dipalmitoyl derivative in the fetal lung. Lung washings from a full-term lamb fetus contain about 10 times more dipalmitoyl lecithin than those from immature fetuses (Brumley et al., 1967a). The lecithin content of rabbit lung also increases with increasing gestational age and reaches maximum value at term (Gluck et al., 1967). Surfactant concentration in lung tissue and lung washings in infants dying of hyaline membrane disease is significantly lower than that in infants whose death is due to factors not related to lung function (Avery and Mead, 1959; Adams et al., 1965; Brumley et al., 1967b).

The lecithin concentration of the fetal lung seems to be reflected in the amniotic fluid. This is supported by the close similarity between the protein, phospholipid, and fatty acid composition of the fetal pulmonary fluid and amniotic fluid (Gluck et al., 1971; Scarpelli, 1967). The surface tension of amniotic fluid, however, is influenced by the presence of various factors including bile salts, salts of free fatty acids, and proteins. At term, unlike fetal pulmonary fluid, it shows high surface tension, and this has been attributed to the inhibitory influence of neutral lipids present (Adams and Fujiwara, 1963; Fujiwara et al., 1964). Attempts by Fozzard and White (1972) to predict the potential risk of R.D.S. in the newborn by measuring amniotic fluid surface tension by using bubble stability, a modification of Prattle's (1958) classical method, also probably failed for this among other reasons. Clements et al. (1972), however, suggest that with the addition of ethanol to amniotic fluid only double chain phospholipids would compete effectively for the surface film. They claim an excellent correlation between the results of this form of bubble stability test and neonatal respiration.

The results of the present study suggest that a positive bubble stability test may be of great value, for it practically excludes the possibility of neonatal R.D.S. However, in only one of 37 cases with a positive result was gestation less than 37 weeks. The main clinical problem in deciding on premature delivery lies with cases which range between 32 and 37 weeks, and it is here that the bubble stability test has proved disappointing. Of 19 cases tested during this stage of pregnancy and delivered within 48 hours none gave a positive result, 14 were negative, and five were intermediate. Yet in 13 of these 19 cases neonatal respiration was perfectly normal. On the basis of the bubble test results, delivery would have been postponed in all cases, a delay which would have been unnecessary in the 13 who breathed normally and might have been dangerous if the fetus was in jeopardy. In contrast the amniotic fluid lecithin concentration was above $3.5 \mathrm{mg} / 100 \mathrm{ml}$ in all the cases where the infant breathed normally and below this level in those who did not. Although the bubble test is of value when positive, it falls short of expectations during the vital gestation range of 32 to 37 weeks. It might function as a screening test in cases where the delivery was planned at the 38th week or later in pregnancy as a safeguard against unsuspected miscalculation of gestation. Many clinicians, however, would be unwilling to perform amniocentesis in every patient in this category. A negative or an intermediate result (observed in $23.5 \%$ even after the end of 39th week) would have to be checked with measurement of lecithin concentration.

An attempt was made to improve the predictive value of the test by modifying the end point. The presence of any large stable bubbles in a tube after 15 minutes was regarded as a positive result in that tube rather than the presence of a complete ring of bubbles. Of the 80 samples of amniotic fluid obtained within 48 hours of delivery which were assayed using this modified end point 46 gave a positive result, 26 an intermediate, and eight a negative result. It is shown in table IV that although this modification increased the number of positive results to 46,

TABLE IV-Relation between a Modified Interpretation of Amniotic Fluid Bubble Stability in Ethanol and Neonatal Respiration in 80 Cases Delivered within 48 Hours of the Test

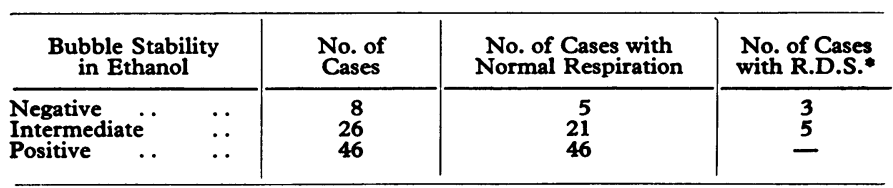

* Two cases with intermediate results died soon after birth and had hypoplastic atelectatic lungs at necropsy.

all with normal neonatal respiration, there were still 34 with negative or intermediate results but normal neonatal respiration in 26.

Even with this less demanding interpretation, therefore, the test still gives too many false negative results. Despite this, we have been impressed by the ingenious idea of Clements et al. (1972) for modifying the bubble stability in amniotic fluid by 
adding ethanol, and are investigating further modifications in the hope of finding a simple yet reliable method for assessing fetal pulmonary maturity in routine clinical practice. At present, in our opinion, biochemical assay of amniotic fluid lecithin level provides the most reliable assessment.

We thank Mrs. Pam Welten for expert technical help. We are grateful to the medical and nursing staff of the Maternity Hospital, Cardiff, for the collection of amniotic fluid samples, and to the Association of Commonwealth Universities for a scholarship to S.G.B.

\section{References}

Adams, F. H., and Fujiwara, T. (1963). Fournal of Pediatrics, 63, 537. Adams, F. H., Fuiiwara, T., Emmanouilides, G., and Scudder, A. (1965). Fournal of Pediatrics, 66, 357.
Avery, M. E., and Mead, J. (1959). American fournal of Diseases of Children, $97,517$.

Bhagwanani, S. G., Fahmy, D., and Turnbull, A. C. (1972a). Lancet, 1, 159.

Bhagwanani, S. G., Fahmy, D., and Turnbull, A. C. (1972b). Lancet, 2, 66. Brumley, G. W., Chernick, V., Hodson, W. A., Normand, A. F., and Avery, M. E. (1967a). Fournal of Clinical Investigation, 46, 863.

Brumley, G. W., Hodson, W. A., and Avery, M. E. (1967b). Pediatrics,

Clements, J. A., et al. (1972). New England fournal of Medicine, 286, 1077. Fozzard, C. E., and White, R. H. (1972). Lancet, 1, 442.

Fujiwara, T., Adams, F. H., and Scudder, A. (1964). Fournal of Pediatrics, 65,824 .

Gluck, L., Kulovich, M. V., Borer, R. C. jun., Anderson, G. G., and Spellacy, W. N. (1971). American Fournal of Obstetrics and Gynecology, 106,440 . Gluck, L., Sribney, M., and Kulovich, M. V. (1967). Paediatric Research,
1, 247.

Nelson, G. H. (1972). American fournal of Obstetrics and Gynecology, 112, 827.

Prattle, R. E. (1958). Proceedings of the Royal Society. Series B. Biological Sciences, 148, 217.

Scarpelli, E. M. (1967). Pediatrics, 40, 951.

\title{
Hydroxyurea, Leucopheresis, and Splenectomy in Chronic Myeloid Leukaemia at the Problastic Phase
}

\author{
L. SCHWARZENBERG, G. MATHÉ, P. POUILLART, R. WEINER, J. LOCOUR, J. GENIN, \\ M. SCHNEIDER, FRANCOISE DE VASSAL, M. HAYAT, J. L. AMIEL, J. R. SCHLUMBERGER, \\ C. JASMIN, C. ROSENFÉLD
}

British Medical fournal, 1973, 1, 700-703

\section{Summary}

Forty-three patients with chronic myeloid leukaemia have been treated with hydroxyurea in order to be subjected to leucopheresis for white cell transfusions. Hydroxyurea decreases leucocytosis when it is administered and the blood granulocyte number increases soon after the drug is stopped. The survival of the patients is not different from the survival of the patients treated with conventional chemotherapy (busulphan, mitobronitol) and it is superior to the survival of patients treated with external radiotherapy or with ${ }^{32}$. Half of the patients were subjected to splenectomy during first remission for a phase II trial. They were not randomized, but the distribution according to age was similar in the two groups. A slight difference appears in favour of splenectomy so far as survival is concerned, but there were three postoperative deaths out of 18 patients. We conclude that a

\footnotetext{
Unité Fred-Siguier, Institut de Cancérologie et d'Immunogénetique (I.C.I.G.), Hopital Paul-Brousse, 14 et 16 Avenue Paul-Vaillant(I.C.I.G.), Hopital Paul-Brousse, 14

L. SCHWARZENBERG, M.D.

G. MATHE, M.D.

P. POUILLART, M.D.

R. WEINER, $M$.

Service d'Hematologie et autres services de l'Institut GustaveRoussy, 16 Bis Avenue Paul-Vaillant-Couturier, 94800 Villejuif, France

J. LACOUR, M.D.

J. GENIN, M.D.

M. SCHNEIDER, M.D.

FRANCCOISE DE VASSAL, M.D.

M. HAYAT, M.D.

J. L. AMIEL, M.D.

I. R. SCHLUMBERGER, M.D.

C. JASMIN, M.D.

C. ROSENFELD, M.D.
}

phase II trial on the value of splenectomy is indicated ethically, but that the patients should be operated on and nursed in a microbiologically controlled environment.

\section{Introduction}

During the past 10 years a few malignant diseases of the haemopoietic and lymphatic systems have been the subject of considerable therapeutic advance. In two of them-acute lymphatic leukaemia (Mathé et al., 1973) and Hodgkin's disease (Mathé and Tubiana, 1973)-the possibility of a cure is nearing reality. On the other hand, the prognosis of chronic myeloid leukaemia (C.M.L.) seems to have changed very little. This is all the more disappointing as "myeloid" cells that proliferate at the beginning of the disease are very sensitive to radiotherapy (Bauer and Hartweg, 1962; H. Schoen and $\mathbf{R}$. Bauer, personal communication) and to several drugs which have become available in the past two decades-namely busulphan (Bernard et al., 1955; Galton and Till, 1955), mitobronitol (Sellei and Eckhardt, 1963; Mathé et al., 1964), demecolcine (Moeschlin et al., 1954; Cattan et al., 1966), piposulfan ( $N, N^{n}$-bis-(3-methanesulfonoxypropanoyl) piperazine) (Kenis, 1968), and hydroxyurea (Fishbern et al., 1964; Cat$\tan$ et al., 1966). The explanation for this lack of progress appears to be the inevitable occurrence of a blastic proliferation ("blastic crisis") in patients who do not die from therapeutic or other medical accidents. This means that C.M.L. can be considered as the forerunner of an acute leukaemia. This concept underlies the strategy of the current E.O.R.T.C. "leukemia and hematosarcoma" group C.M.L. therapy protocol, which is designed to test the value of prophylactic antiblastic treatment.

The main object of this study was to settle a logistic and ethical problem which arose when Freireich et al. (1964) and our group (Schwarzenberg et al., 1965) showed that C.M.L. white cell transfusates contain physiologically active leucocytes that can cure agranulocytosis. The question then 